\title{
Do-it-Yourself Activities and Subjective Well-Being
}

\section{Ann Futterman Collier ${ }^{1}$ (D) $\cdot$ Heidi A. Wayment ${ }^{1} \cdot$ Marco Wolf $^{2}$}

Accepted: 22 April 2020 / Published online: 9 May 2020

(C) Springer Nature Switzerland AG 2020

\begin{abstract}
We examined predictors of subjective well-being (SWB) associated with do-it-yourself (DIY) activities in a sample of 525 self-identified DIYers through Amazon's Mechanical Turk. We hypothesized that positive mood, feeling energized or aroused, and experiencing flow during DIY activities, would each contribute to subjective wellbeing (SWB), and, that negative self-focus would not. We also controlled for individual differences that could affect the experience of negative self-focus and flow: quiet ego and depression/anxiety. Overall, participants identified most with DIY activities that involved aesthetics, repair, upkeep and maintenance, and landscape or gardening, and construction; they reported these activities were challenging and utilized their skills. Using structural equation modeling, we examined our hypothesized model and two alternate models. Our amended hypothesized model accounted for $61 \%$ of the variance in SWB. Positive mood/arousal was positively associated with SWB. Quiet ego facilitated SWB, both directly and indirectly through the positive mood/high arousal pathway. Depressed and anxious mood was negatively associated with flow during DIY activities and SWB; it was also positively correlated with excessive self-focus during DIY activities. Our results lend credence to the idea that DIY activities that induce positive mood and high arousal may benefit SWB. Having a strong quiet ego identity may enhance the benefits associated with DIY activities. Our study contributes to the literature by describing the mechanisms responsible for how DIY activities promote SWB, as well as by explaining the factors that optimize the impact of these experiences.
\end{abstract}

Keywords Do-it-yourself activities · Subjective well-being $\cdot$ Flow $\cdot$ Positive mood and arousal $\cdot$ Negative self-focus

Ann Futterman Collier

ann.collier@nau.edu

1 Department of Psychological Sciences, Northern Arizona University, Social and Behavioral Sciences Building, PO Box 15106, Flagstaff, AZ 86011-5106, USA

2 Department of Marketing, University of Southern Mississippi, Hattiesburg, USA 
Do-it-yourself (DIY) activities encompass a variety of undertakings from home improvement to self-service, from crafts to art making, and from design work to digital technologies. Nearly $40 \%$ of all Americans considered starting a DIY project in 2013 and this number continues to increase (Williams 2013). Despite the substantial growth in DIY activities, very few social scientists have studied the psychology behind DIY. Wolf and McQuitty (2011) suggested a consumer behavior model to explain motivations and outcomes associated with DIY. They asserted that marketplace motivations and identity factors drive the participation in DIY and reported a link between physical DIY involvement and higher order outcome values, with implications to life goals (Wolf and McQuitty 2011; Wolf and McQuitty 2013). Other investigators have reported forms of knowledge sharing, open source contributions, learning, and creativity as the core motivational forces underlying DIY involvement, rather than profit and social capital (Kuznetsov and Paulos 2010; Williams 2008; Wolf and Ritz 2018). Wolf et al. (2015) suggested that DIY engagement is motivated by feelings of empowerment.

Another reason people may choose to participate in DIY activities is that DIY contributes towards their overall subjective well-being (SWB). The term SWB refers to the type of broad appraisals people make about their lives, such as about life and health satisfaction, as well as specific feelings that reflect responses to life circumstances and events (Diener et al. 2017). SWB has been operationally defined as a composite of life satisfaction, positive affect, and negative affect (Diener 1984; Diener 1994; Diener et al. 1999; Diener et al. 2015; Sheldon and Lyubomirsky 2006). It has been studied for many decades and appears to be associated with excellent health and greater longevity (e.g., Diener and Chan 2011; Lyubomirsky et al. 2005a, 2005b), and strong social relationships and prosocial behavior (e.g., Diener and Seligman 2002; Lount Jr. 2010). More recently, researchers have found that brief positive psychological interventions can increase SWB, such as when cultivating gratitude (e.g., Lyubomirsky et al. 2005a, 2005b; Lyubomirsky et al. 2011), performing acts of kindness (e.g., Sheldon et al. 2012), savoring experiences (e.g., Bryant and Veroff 2007), and writing about positive experiences (e.g., Pinquart and Forstmeier 2012). Thus, although genetics and circumstantial factors influence SWB (e.g., Lyubomirsky et al. 2005a, 2005b), volitional and intentional activities may account for as much as $40 \%$ of the variance in the experience of happiness or SWB (Lyubomirsky and Layous 2013; Lyubomirsky et al. 2005a, 2005b; Sheldon and Lyubomirsky 2006; Sheldon and Lyubomirsky 2019). Furthermore, Lyubomirsky et al. (2011) have reported that people who invest more effort in positive activities report greater improvement in their overall well-being. In turn, these positive activities positively influence individual set points of happiness. Given the surge of involvement with DIY activities, it is possible that DIY activities elevate SWB and as such, users may be motivated to participate in DIY because they are pursuing interests that bring them pleasure and enhance happiness. Likewise, happier people may be more likely to practice DIY activities, which further reinforces their happiness.

The current study is the first large-scale investigation to examine SWB, or composite happiness (Demir and Weitekamp 2007), in people who engage in DIY activities, as well as to study the mechanisms that could explain how DIY activities contribute towards SWB. Based on previous research, we propose a model we call "PEARLS" to help explain how people derive benefits from DIY activities (Collier and Wayment 2019a). The PEARLS model posits that when people participate in personalized (P) 
activities (such as DIY) that are high in engagement (E) (or flow) and arousal (A) and low in rumination (R) (or self-focus), they are most likely to experience life satisfaction (LS), or more comprehensively, SWB. After briefly describing the PEARLS model components below, we examine the impact of two important individual difference characteristics that may help or hinder SWB in people that participate in DIY: quiet ego identity (Wayment 2008) and depression/anxiety. In the following paragraphs, we provide justification for how these variables each contribute towards or deter from SWB in adults. Fig. 1 provides a visual overview of our model.

\section{Flow and Engagement}

Flow refers to activities that are engrossing, involving intense focus and attention, and are absorbing. Csikszentmihalyi (1990) explained that creative tasks which are characterized by clear goals, immediate feedback, and sufficient challenge, lead to "flow" experiences. Although Csikszentmihalyi's original research focused on professionally trained athletes and artists, flow occurs during a number of activities ranging from composing music to engaging in housework (Asakawa 2004). Flow has been associated with many benefits, including overall happiness and well-being (e.g., Collins et al. 2009; Griffiths 2008; Rogatko 2009; Sahoo and Sahu 2009) as well as increased healthrelated quality of life (Hirao et al. 2012) and decreased depression (Mosing et al. 2018). Engagement, a component of flow, has also been reported as a critical factor that contributes to longer-lasting mood-repair and SWB during maker activities (Collier 2011; Collier and von Károlyi 2014; Collier et al. 2016; Collier and Wayment 2018). High engagement and flow during DIY could then lead to greater productivity and

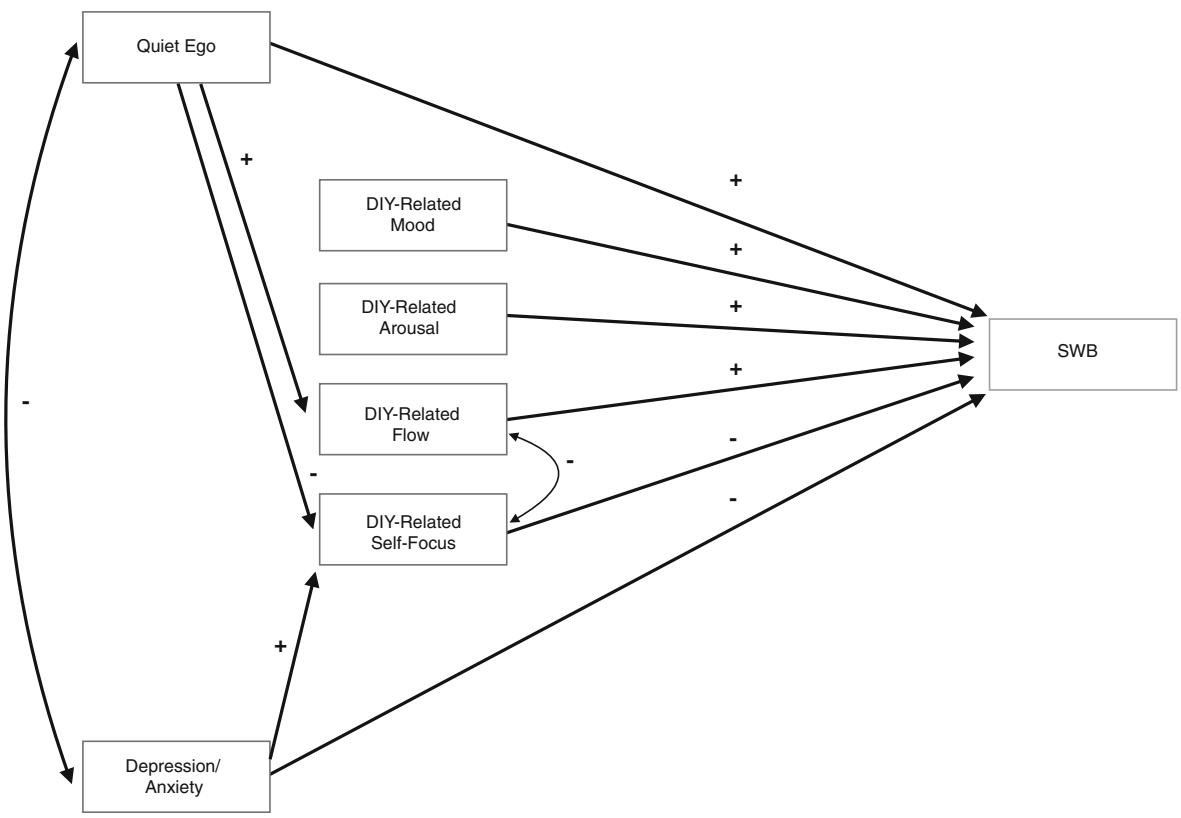

Fig. 1 Theoretical model 
success with DIY, which would further enhance SWB. Collier and Wayment (2018) did not examine their participants' report of engagement during Maker activities. To date, no investigators have reported on the role of flow or engagement during DIY, or, whether they contribute towards overall SWB during these types of activities.

\section{Arousal and Positive Mood during DIY}

Feldman Barrett and Russell (1999) have suggested that affect is best described by two independent dimensions: the positive and negative quality of the mood state (valence), as well as the degree of activation or arousal. Mood valence states are often negatively correlated with one another (typically -.90; Carroll et al. 1999) and these dimensions are usually described as ranging from pleasant to unpleasant. Activation, or arousal can be described as the experience of feeling stimulated, activated, or energized, as opposed to a state of calm or low energy. Arousal, in this context, does not refer to physiological arousal, but instead to dimensions of the conscious experiences (Barrett and Russell 1999). Even though there are individual differences in the co-occurrence of mood valence and arousal (Kuppens 2008), there is typically a weak but consistent V-shape association between them: arousal is often a function of pleasant valence (Kuppens et al. 2013). Interestingly, Feldman Barrett and Russell (1999) have suggested that the dimensions of mood valence and arousal should not be combined, nor should one be emphasized over the other.

Consistent with Kuppens et al. (2013), Collier and colleagues have reported that high positive mood and high arousal occur together during art-making and crafting (Collier and von Károlyi 2014; Collier et al. 2016; Collier and Wayment 2018). Possibly, Maker and DIY activities lend themselves towards enhancing both positive mood and arousal levels, which may help explain the association with increased SWB during Maker activities. Mood enhancement occurs when a person is able to counteract negative mood. Investigators have found that a broad range of both therapeutic (Augustine and Hemenover 2009; Naragon-Gainey et al. 2017; Thayer et al. 1994) and non-therapeutic creative activities (e.g., Collier 2011; Dalebroux et al. 2008; Pöllänen 2015a, 2015b) can serve to change, promote, and restore positive mood. The ability to regulate emotions, such as by positive mood enhancement, is a critical target in most, if not all psychological interventions (e.g., Gratz et al. 2015) and likely contributes to SWB. Likewise, moderate to high arousal states are known to accompany the viewing of art (Brinck 2017; Marin et al. 2016), and, seem to contribute towards wellness (Kuppens et al. 2013), emotional regulation (Thayer et al. 1994), and subjective well-being (SWB; Collins et al. 2009). It is reasonable, therefore, to surmise that one reason people are motivated to engage in DIY activities is because it leads them to experience more positive mood and higher arousal levels.

The relationship between mood, arousal, and SWB was recently supported by Collier and Wayment (2018) who examined the mood enhancing qualities of a lowtechnical type of DIY, called "Maker" activity. They defined Maker activities as including a wide range of hands-on, everyday behaviors such as gardening, baking, cooking, scrap booking, photographing, and sewing. College students reported that Maker activities helped them to purposefully enter a positive present-focused state (Collier and Wayment 2018). In a later study, the same authors also found that high 
arousal was the most critical factor that mediated SWB during Maker activities (Collier and Wayment 2019a). To date, no other investigators have examined the role of mood and arousal during DIY activities in adults who self-identify as DIYers.

\section{Quiet Ego, Reduced Self-Focus, and Rumination}

"Quiet ego" describes a person's motivational readiness to think, feel, and behave in ways that are less self-focused and more growth oriented (Wayment 2008; Wayment et al. 2015; Wayment and Bauer 2018). Quiet ego is associated with several types of positive psychological outcomes, including generativity, self-compassion, meaning in life, resilience, and savoring, and adaptive self-regulation, as well as SWB (Wayment et al. 2015; Wayment and Bauer 2017; Wayment and Bauer 2018; Wayment et al. 2016). The relevance of the quiet ego construct for the present study is not only the robust association between quiet ego and SWB (cf. Wayment and Bauer 2017), but because reduced self-focus, known to be associated with high quiet ego scores, may be an important explanatory factor for why people derive positive benefits from DIY activities. For example, Wayment and colleagues reported that reductions in self-focus were associated with greater emotional regulation skills, self-control, and reduced stress (Wayment et al. 2015; Wayment et al. 2016). Collier and Wayment (2019b) have found that higher quiet ego scores were associated with lower self-focus during an engaging virtual reality activity. While we anticipate that people who regularly engage in DIY will have higher quiet ego scores, we also anticipate there are independent pathways between quiet ego and flow, as well as quiet ego and excessive negative self-focus during DIY activities. We also anticipate that quiet ego will be negatively associated with depression.

When people are depressed, they are more likely to excessively focus on themselves, by ruminating (Nolen-Hoeksema et al. 2008). Rumination is a type of stress response where people repetitively focus on their negative mood, as well as the possible causes and consequences of their depressive symptoms (Nolen-Hoeksema et al. 2008). Rumination is a catalyst for negative mood, and, is associated with poorer problem solving, which are both deterrents for positive mood enhancement. Rumination also interferes with the ability to fully engage in optimal activities, thereby minimizing or reducing positive psychological benefits from work and leisure activities (e.g., Peifer et al. 2015; Rusting and Nolen-Hoeksema 1998). For example, greater depression is associated with less engagement in daily activities that bring pleasure (e.g., McAndrew et al. 2017) and behavioral activation, the encouragement of becoming more active and engaged in life, is a useful intervention strategy for people experiencing dysphoria and depression (e.g., Chartier and Provencher 2013; Martin and Oliver 2018; Soucy et al. 2013). Previous studies have also shown that the quiet ego is negatively associated with measures of depression and anxiety (Collier and Wayment 2019b; Wayment and Brookshire 2018; Wayment and Silver 2018; Wayment and Walters 2017). In accordance with the literature, we would anticipate that depressive symptoms are associated with ruminative self-focus during DIY activities, and that both depression and rumination during DIY are associated with lower SWB. This is because the pathway for arousal, positive mood, and flow leading to SWB would be thwarted for people who are depressed. In addition, self-focus would interfere with flow. In our 
model, the existence of depression would suggest few, if any, benefits derived from DIY and a negative association with quiet ego scores.

\section{Theoretical Model}

In the current study we add to the existing literature by studying a sample of experienced, adult DIYers. We also examine the mechanisms that contribute to SWB in people who engage in DIY: individual PEARLS characteristics, i.e., mood, arousal, flow, and excessive self-focus. Finally, we seek to explain the factors that could optimize (quiet ego) or hinder (depression/anxiety) the impact of these experiences.

Please refer to Fig. 1 for our theoretical model. First, we expected that selfreported mood, arousal, and flow during DIY activities would be positively related to SWB. Second, we expected that quiet ego scores would be associated with greater depression, greater flow, lower self-focus, and higher SWB. Third, we expected that depression/anxiety would be associated with increased self-focus and hence lower engagement or flow during DIY activities; we also anticipated depression/anxiety would be associated with lower SWB. Finally, using path analysis, we explored the relationships amongst all of the variables of interest in order to best understand the direct and indirect roles of pre-existing characteristics, such as quiet ego and depression; DIY-related responses, i.e., arousal, flow, mood, and self-focus; and SWB.

\section{Method}

\subsection{Participants}

The sample was collected through Amazon's Mechanical Turk (MTurk), an online method of accessing a large participant pool by posting tasks online and providing a monetary compensation for survey completion (Buhrmester et al. 2011). The authors used this platform in order to reach a broad, adult audience of skilled DIYers who were willing to share psychological details of their experience. After completing a 15-min online survey using the Survey Monkey platform, participants were given a small monetary incentive of $\$ 1.50$. A total number of 627 participants initially completed the online questionnaire; the final sample included 525 participants. Sixteen participants were excluded because more than $10 \%$ of their data was incomplete. We then excluded additional participants because they failed the quality selection criteria (Buhrmester et al. 2011). For quality selection, participants were first asked to indicate which of four categories of DIY activities they preferred to engage in. Then, they were asked to describe the specific activities they enjoyed. Excluded participants either left this second question blank or they provided an answer that was inconsistent with DIY. For example, one excluded participant indicated he/she enjoyed activities in the category "constructing something new." However, the same person then described their favored DIY activity as "keeping quiet," with no other details provided. Because so many participants from international countries did not provide the correct 
information for the "type" of DIY activities, it was decided to exclude all participants located outside the US ( $n=554$ participants lived in the USA). All study procedures were approved by the Institutional Review Boards at each of the authors' respective universities.

\subsection{Measures}

DIY Activities To measure DIY activities, we collapsed Wolf and McQuitty's (2013) 46 DIY activities into four categories: 1) repair, upkeep, or maintenance; 2) constructing something new; 3 ) aesthetics: make interior or exterior more beautiful; and 4) landscape and gardening. Using a modified version of Waterman et al.'s (2008) Personally Expressive Activities Questionnaire (PEAQ; Collier and von Károlyi 2014), survey participants were asked to identify the DIY activity that best described them: "If you wanted another person to know about who you really were, what you were really like as a person, which type of Do-It-Yourself (DIY) activity (or activities) listed below would you tell them about that truly reflects who you are, right now? Please look at the categories of activities below and select one." Participants were then asked to describe more specifically the type of activities they most enjoyed doing, within the above category. Using a 7-point scale, participants were also asked to indicate what their usual level of interest was when engaged in this type of DIY activity $(1=$ very low; $4=$ not high or low; $7=$ very high), as well as how frequently they engaged in the DIY activity over the past year $(1=$ very seldom; $4=$ in between seldom and frequently; $7=$ very frequently).

DIY Effort and Challenge Participants were asked to report on the level of effort/ challenge associated with their PEAQ activity (Waterman et al. 2008) with the following questions: "What is the usual level of effort and investment when you engage in this activity?" and "How challenged do you feel by this activity?" Participants rated their effort and challenge using a 7-point scale $(1=$ very low; $4=$ neutral, neither low nor high; and $7=$ very high).

DIY Arousal and Mood Items used for the assessment of mood and arousal were based on questions developed from Collier and von Károlyi (2014) and Feldman Barrett and Russell (1999). For mood, participants were asked to consider their experiences while participating in their preferred category of DIY activity, and then rate mood as follows (four items): "My mood always feels more positive during the activity;" "My mood always feels more positive after the activity;" "I feel rejuvenated, e.g., refreshed, restored, and revitalized, during the activity;" and "I feel rejuvenated, e.g., refreshed, restored, and revitalized) after the activity." For each rating, participants used a 7-point scale ( $1=$ not at all like me; $4=$ neutral; 7 = very much like me). An average "mood" score was created that combined the rejuvenated and mood questions; Cronbach's Alpha $=.82$.

For arousal, participants were asked the following questions, using the same 7-point scale $(1=$ not at all like me; $4=$ neutral; $7=$ very much like me): "I feel energized, stimulated, aroused, or activated during the activity;" and "I feel energized, stimulated, aroused, or activated after the activity." We created an average arousal score that combined these two arousal questions; Cronbach's Alpha $=.67$. 
DIY Flow We measured engagement using the "flow" subscale items from the PEAQ (Waterman et al. 2008). The eight PEAQ flow questions asked participants if they had clear goals, felt self-conscious, felt in control, lost track of time, knew how well they were doing, had a high level of concentration, forgot personal problems, and felt fully involved while engaged in their favorite DIY activity. These questions were rated using a 7-point scale ( $1=$ not at all like me; $4=$ neutral; $7=$ very much like me). The item "feeling self-conscious" was reversed coded. Cronbach's alpha for these eight items was .74 . A score was then created by averaging the eight items.

DIY Self-Focus We defined self-focus as maintaining a repetitive focus on problems while engaged in DIY activities. To evaluate this, we adapted the ruminative or brooding subscale from the Ruminative Response Scale (RRS; Treynor et al. 2003). Instead of the usual RRS instructions, participants were asked "When you are involved in these types of DIY activities, how much do you think about problems that are bothering you (while doing your DIY activities)? Please read each of the items below and indicate whether you almost never, sometimes, often, or almost always think or do each one when you are involved in your favorite DIY activity." The items were as follows: "What am I doing to deserve this?" "Why do I always react this way?" "Think about a situation, wishing it had gone better," "Why don't I handle things better?" and "Why do I have problems other people don't have?" Participants used a 4-point scale $(1=$ almost never to $4=$ almost always) for these five items. Cronbach's alpha for these items was $\alpha=.86$; the five items were then averaged into one self-focus score.

Quiet Ego The Quiet Ego Scale (QES; Wayment et al. 2015) is a 14-item measure that reflects individual differences in what Wayment (2008) have called a "quiet ego," or a self-identity that is grounded in growth-related values and an ability to balance self- and other concerns (Wayment and Bauer 2017; Wayment and Bauer 2018). Quiet ego scale scores are strongly associated with self-transcendent and growth-related values and goals (Wayment and Bauer 2018). Participants answered all questions on a 5-point scale ( 1 = strongly disagree; 5 = strongly agree) (e.g., "I think it is important to have new experiences that challenge how you think about yourself and the world," or "I feel a connection to all living things"). Five items on the QES are reverse coded (e.g., "I find myself doing things without paying much attention" or "I rush through activities without being really attentive to them. Cronbach's alpha was .87; an average score was created for QES.

Depression/Anxiety Depression and anxiety were assessed using the Patient Health Questionnaire (PHQ-4) by Kroenke et al. (2009). The PHQ-4 is a four item-screening tool for depression and anxiety, originally developed from the Primary Care Evaluation of Mental disorders (PRIMEMD; Spitzer et al. 1999). Kroenke et al. (2009) reported increasing PHQ-4 scores were strongly associated with functional impairment, disability days, and health care use; and anxiety had a substantial effect on functional status that was independent of depression. The PHQ-4 is based on a 4-point scale ranging from $0=$ never to $4=$ always. Participants rate the items by indicating their experience over the previous two weeks. The two items evaluating depression are as follows: feeling down, depressed or hopeless; little interest or pleasure in doing things. he two 
items assessing anxiety are as follows: feeling nervous, anxious or on edge; not being able to stop or control worrying. Cronbach's alpha was.89. As per scoring suggestions, a summary depression/anxiety score was determined by adding together the scores for each of the 4 items (Kroenke et al. 2009).

Subjective Well-Being (SWB) Based on the work of Diener et al. (1999) and Demir and Weitekamp (2007), we created a happiness score, described herein as the SWB score (again, also sometimes referred to as a composite happiness score), that combined a standardized life satisfaction score with a standardized measure of positive and negative affect. First, satisfaction with life was assessed with the Diener et al. (1985) Satisfaction with Life Scale (SWLS). The five-item measure is designed to assess overall cognitive judgement of one's satisfaction with life. The measure uses a 7-point Likert scale ( 1 = "strongly disagree;" 7 = "strongly agree"). Reliability ratings were very strong, $\alpha=.93$.

Second, the Positive and Negative Affect Schedule (PANAS) (Watson et al. 1988) was used to assess positive and negative mood. Participants were asked: "Please think about yourself and how you normally feel. To what extent do you generally feel the following?" Participants used a 5-point scale $(1=$ very slightly and 5 =extremely) and rated 10 items for positive affect (e.g., determined, inspired); and 10 items for negative affect (e.g., upset, hostile). Cronbach's alphas were .89 for the positive and negative scales. Average scores were then created for the SWLS and PANAS subscales. The scores were standardized and then SWB was derived by using the following formula: $S W B=$ (positive affect + life satisfaction) - negative affect (Demir and Weitekamp 2007).

\section{Results}

\subsection{Sample Description}

Our participants were split between males (51\%) and females (49\%). The age categories indicated that $34 \%$ were between 18 and 29 years; $34.7 \%$ were between 30 and 39 years; $15.7 \%$ were between 40 and 49 years; $10 \%$ were between 50 and 59 years; and $5.6 \%$ were older than 60 . The largest income category $(21.1 \%)$ was $\$ 50,000$ $\$ 74,999$ annually. Over half of the respondents (59.4\%) were employed full time; $20.8 \%$ were part time employees; and $19.8 \%$ were not employed, retired, or homemaker. Most participants had completed high school or the equivalent (43.4\%); $44.4 \%$ had completed a 4-year college degree. The majority of participants were Caucasian $(82.9 \%)$; followed by Asian (8.2\%), Latino or Hispanic (5.5\%), and African American $(5.1 \%)$.

Table 1 presents means and standard deviations for the key variables of interest. The SWB, QES, and depression/anxiety scores were all within the normal ranges published by previous authors (Demir and Weitekamp 2007; Kroenke et al. 2009; Wayment 2008; Wolf and McQuitty 2013). In addition, our reported rates of DIY occurred almost equally in women and men, which is also consistent with previous literature (Wolf and McQuitty 2013). 
Overall, the participants identified most with DIY activities involving aesthetics: making interior or exterior more beautiful (30.3\%); followed by repair, upkeep and maintenance $(27.1 \%)$; followed by landscape or gardening $(22.7 \%)$; and then constructing new things (21\%). Not surprisingly, the participants rated their interest in their DIY activity as strong, $M=5.72(1.01)$, range 1 to $7,95 \%$ CI $[5.63,5.80]$. These were also activities participants reported regularly engaging in, $M=5.28(1.14)$, range 1 to 7 . Participants reported that their DIY activity required greater than average skill, $M=$ $5.77(0.97), 95 \% \mathrm{CI}[5.69,5.85]$, as well as it was challenging, $M=5.26(1.13), 95 \% \mathrm{CI}$ $[5.16,5.36]$.

Table 1 also provides the zero-order correlations for the key variables. All of the correlations were of the expected strength and in the expected direction, as suggested in Fig. 1, confirming each of our hypotheses. Thus, self-reported mood, arousal, and flow during DIY activities were each significantly correlated with SWB. Quiet ego scores were also significantly associated with greater depression, greater flow, lower selffocus, and higher SWB. Finally, depression/anxiety was significantly associated with increased self-focus and lower engagement or flow in the DIY activity; it was also associated with significantly lower SWB.

We were surprised at the strength of the correlation between positive mood and arousal. As such, we decided to combine the mood and arousal variables in the subsequent path model analyses. Please note that the new combined 4-item mood and 2 item arousal measure (called mood/arousal) was Cronbach's alpha was .88.

\subsection{Path Model}

We used EQS (Bentler 2006) to test a total of four path models: our original hypothesized model (Fig. 1), our hypothesized model with an amendment (Fig. 2), and two alternate models. For all models, 22 subjects were excluded due to missing data and 20 were removed to improve indices of multivariate kurtosis. Our final sample included 483 participants. The paths specified in the model were informed by our hypotheses (see Fig. 1) and our correlational results (see Table 1). Model fit indices for all path models can be found in Table 2 .

Table 1 Correlations for Psychosocial Variables in Do-It-Yourself Sample $(n=525)$

\begin{tabular}{|c|c|c|c|c|c|c|c|c|c|c|}
\hline & $M$ & $S D$ & $95 \% \mathrm{CI}$ & 1 & 2 & 3 & 4 & 5 & 6 & 7 \\
\hline 1. Subjective Well-being & 0.07 & 2.17 & $\begin{array}{r}-0.121 \\
0.255\end{array}$ & - & & & & & & \\
\hline 2. Quiet Ego & 5.17 & 0.47 & $5.08,5.24$ & $.57 * *$ & - & & & & & \\
\hline 3. Depression/Anxiety & 1.98 & 2.69 & $1.75,2.21$ & $-.67 * *$ & $-.37 * *$ & - & & & & \\
\hline 4. Self-focus during DIY & 7.43 & 2.94 & $7.18,7.68$ & $-.15^{*}$ & $-.22 * *$ & $.29 * *$ & - & & & \\
\hline 5. Arousal during DIY & 5.82 & 0.91 & $5.74,5.90$ & $.39 * *$ & $.41 * *$ & $-.21 * *$ & -.03 & - & & \\
\hline $\begin{array}{l}\text { 6. Positive mood during } \\
\text { DIY }\end{array}$ & 5.72 & 1.02 & $5.63,5.81$ & $.39 * *$ & $.42 * *$ & $-.21 * *$ & -.03 & $.82 * *$ & - & \\
\hline 7. Flow during DIY & 5.60 & 0.77 & $5.54,5.66$ & $.37 * *$ & $.49 * *$ & $-.25 * *$ & $-.26^{* *}$ & $.48 * *$ & $.56^{* *}$ & - \\
\hline
\end{tabular}

Note. $* p<.01 ; * * \mathrm{p}<.001$ 
Because DIY-related variables are dependent variables in the model, the hypothesized correlations between them were specified as error term correlations between flow and mood/arousal, and between self-focus and mood/arousal. QES and depression/ anxiety were also allowed to correlate. The normalized Mardia's coefficient was 7.72, slightly higher due to most likely the somewhat higher skewness and kurtosis of the PHQ measure. The hypothesized model did not fit well, $X^{2}(4)=135.53, p<.0000$, $\mathrm{CFI}=.87, \mathrm{NNFI}=.52, \mathrm{SRMR}=.17, \mathrm{RMSEA}=.26(90 \% \mathrm{CI}[.224, .299])$. Multivariate LaGrange Multiplier tests suggested an additional significant path: from quiet ego to $\mathrm{mood} /$ arousal $\left(X^{2}=87.95, p<0001\right)$. When this path was added, the model fit was good, $X^{2}(3)=11.00, p=.012, \mathrm{CFI}=.99, \mathrm{NNFI}=.96, \mathrm{SRMR}=.035, \mathrm{RMSEA}=.07$ (90\% CI $[.031, .124])$. This amended model fit better than the original model, $X^{2}(1)=124.53, p<.0000$. The average absolute standardized residual coefficient was .019 , and the average off-diagonal absolute standardized residual coefficient was .025 . The error term of flow was positively associated with mood/arousal $(.46, p<.001)$ and negatively associated with self-focus $(-.21, p<.001)$. QES and depression/anxiety were negatively correlated $(-.39, p<.001)$. These correlated error terms are not depicted in the figure.

As shown in Fig. 2, we found QES was significantly associated with all three DIYrelated reactions: greater positive mood/arousal $(.48, p<.001)$, greater flow $(.50$, $p<.001)$, less self-focus $(-.16, p<.001)$, and greater $\operatorname{SWB}(.32, p<.001)$. We also found that, as expected, depression/anxiety was significantly associated with QES $(-.40, p<.001)$, increased self-focus $(.29, p<.001)$ and lower SWB $(-.54, p<.001)$. Of the three DIY-related reactions (mood/arousal, flow, self-focus), only positive $\mathrm{mood} /$ arousal had a significant association with $\operatorname{SWB}(.16, p<.001)$, controlling for the significant relationships between SWB and QES and depression/anxiety. QES was

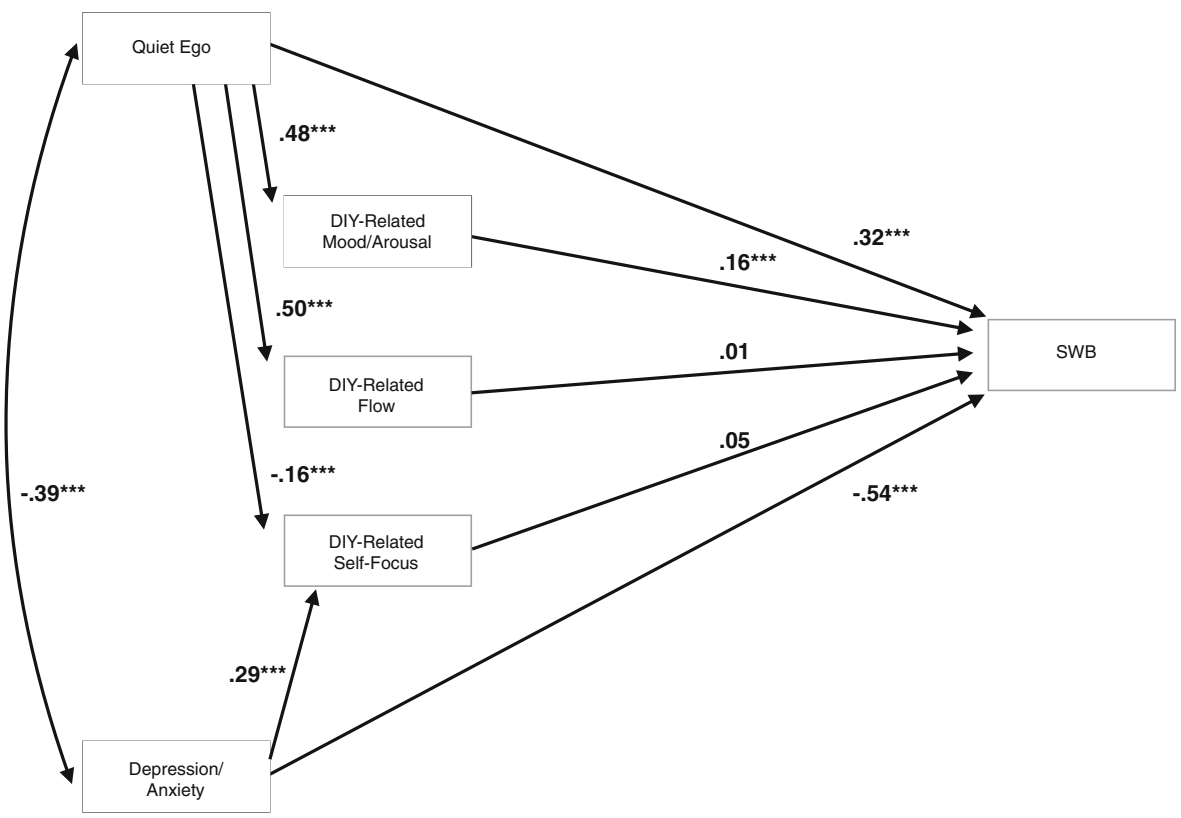

Fig. 2 Final model 
Table 2 Goodness-of-Fit Statistics for the Path Model

\begin{tabular}{lrlllllll}
\hline & $X^{2}$ & $d f$ & $p$ & CFI & NNFI & SRMR & RMSEA & RMSEA 90\% CI \\
\hline Original Hypothesized Model & 135.53 & 4 & .0000 & .87 & .52 & .170 & .26 & $.224, .299$ \\
Amended Hypothesized Model & 11.00 & 3 & .012 & .99 & .96 & .035 & .07 & $.031, .124$ \\
Alternate 1 & 342.46 & 5 & .0000 & .67 & .67 & .160 & .37 & $.341, .408$ \\
Alternate 2 & 38.29 & 6 & .0000 & .97 & .92 & .054 & .11 & $.075, .139$ \\
\hline
\end{tabular}

indirectly related to SWB via its relationships with positive mood/arousal (QES: .07, p $<.001$ ). aken together, our hypotheses were largely supported. The model accounted for $61 \%$ of the variance in SWB.

Two alternate models were tested that altered the position of QES and depression/ anxiety. The first alternative posited that SWB is the antecedent driver three DIYrelated outcomes, and these outcomes influence QES and depression/anxiety scores. That is, the DIY-related outcomes help explain how SWB leads to decreased depression/anxiety and stronger quiet ego characteristics. The relationships between QES and DIY outcomes were similar to those found in the amended hypothesized model, as was the relationship between DIY self-focus and depression/anxiety. SWB was a significant predictor of mood/arousal $(.45, p<.001)$, flow $(.41, p<.001)$, and self-focus $(-.26, p<.001)$. In this model, the error terms of QES and depression/anxiety were significantly correlated and SWB was a significant indirect predictor of QES (.27, $p<.001)$ and depression/anxiety $(-.10, p<.001)$. However, the model did not fit well due to large residual correlations the error terms between QES and flow, and between self-focus and depression/anxiety. Twenty eight percent of QES was predicted by model, and $14 \%$ of depression/anxiety. A statistical comparison of this alternate model to the final amended model showed that the amended hypothesized model provided a better fit to the data than the first alternate model, $X^{2}(2)=331.46, p<.0001$.

The second alternate model posited that QES and depression/anxiety mediated the relationship between SWB and the three DIY-related reactions (positive mood/arousal, flow, self-focus). As with the hypothesized model results, paths from QES to all three reactions were specified, and one path between depression/anxiety and self-focus. Error terms of QES and depression/anxiety were allowed to correlate as were the error terms specified in the hypothesized model between flow, positive mood, and self-focus. SWB was significantly associated with QES and depression/anxiety in expected directions. Although the relationships between QES and all three DIY-related reactions, and between depression/anxiety and self-focus were similar to the hypothesized model, QES and depression/anxiety were no longer significantly related. The model predicted $23 \%$ of positive mood/arousal, $25 \%$ of flow, and $15 \%$ of self-focus. A statistical comparison revealed again that the amended hypothesized model provided a better fit to the data that the second alternative model, $X^{2}(3)=27.29, p<.0001$.

Taken together, our results suggest that our amended hypothesized model (Fig. 2), with the added path between QES and positive mood/arousal, was the best fitting model. Further, our first alternative models obscured our main objective, which is to model predictors of SWB. The second alternative model posits that quiet ego and depression/anxiety mediate the relationship between DIY outcomes and well-being. 
This model is not in line with our expectation that QES and depression/anxiety are measuring more stable individual differences and would be more likely to influence the perceptions of DIY experience rather than the converse. Thus, our amended hypothesized model provided a very good fit to the data and highlights the importance of positive mood/arousal during DIY-related activity for SWB in a large sample of DIYers. Further, this model also underscores the role of QES in facilitating positive $\mathrm{mood} /$ arousal during DIY-related activities, controlling for the relationships between QES, depression/anxiety, and SWB.

\section{Discussion}

Correlational analysis confirmed each of our expected hypotheses: self-reported mood, arousal, and flow during DIY activities were each significantly correlated with SWB. Quiet ego scores were also significantly associated with greater depression/anxiety, greater DIY-related flow, lower DIY-related self-focus, and higher SWB. In addition, depression/anxiety was significantly associated with increased DIY-related self-focus and lower DIY-related engagement or flow; it was also associated with significantly lower SWB. Path model analysis allowed us to examine more nuanced relationships between these variables. Although depression/anxiety and quiet ego were each independently associated with SWB, mood and arousal during DIY activities was the most important DIY response associated with SWB, more important than DIY-related flow or DIY-related self-focus.

We had to modify our original path model to accommodate for the strong and significant relationship between positive mood and arousal levels, and, to account for the significant association between quiet ego and mood/arousal. Once amended, the hypothesized model provided a very good fit to the data, explaining $61 \%$ of the variance. Our model highlights the importance of combined positive mood/arousal during DIY-related activity for SWB in a large sample of DIYers. Further, this model underscores the role of quiet ego in facilitating positive mood/arousal and flow during DIY-related activities, while controlling for the relationships between quiet ego, depression/anxiety, and SWB. Additionally, flow was indirectly related to mood/arousal, and, ruminative self-focus during DIY appeared to interfere with the ability to enter a flow state.

Thus, controlling for the impact of quiet ego and depression/anxiety on DIY-related perceptions, positive mood/arousal during DIY activity was the most important variable in predicting SWB for DIYers. These findings were partially supported by recent published results with "Makers" (Collier and Wayment 2018), where arousal during Maker activity was associated with SWB. Although Feldman Barrett and Russell (1999) have suggested that the dimensions of mood valence and arousal should not be combined, our results suggest otherwise. It may be that because positive mood and high arousal occur so frequently together during DIY activities, they should be considered as one unit, not separately.

Our data explorations suggested that higher QES ego scores were positively associated with feelings of arousal and positive mood during DIY activities; as well as with flow and a lack of self-focus during DIY activities. Our results support previous research linking quiet ego with well-being (Wayment et al. 2015; Wayment et al. 
2016). We also add to the literature by suggesting another pathway through which quiet ego is associated with SWB: it reduces self-focus which may allow for an increase in engagement during DIY.

Depression/anxiety was negatively correlated with SWB, QES, and flow during DIY activities. These findings suggest that feelings of depression and anxiety may interfere with the positive benefits of DIY activity. This is not surprising given that one of the hallmarks of both depression and anxiety is difficulty concentrating and attending, as well as decreased engagement in activities. Our findings validate that involvement in more complex activities, similar to DIY, may be difficult for people experiencing depressive or anxiety symptoms.

Our sample of DIYers were comprised equally of males and females, predominantly young to middle-aged Caucasian adults who were typically employed, and college educated. Overall, they were psychologically well-adjusted and capable of maintaining a quiet ego state, that is, of being present focused, capable of perspective-taking, having an inclusive identity, and growth oriented (Wayment 2008). Our sample of DIYers also demonstrated similar rates of overall psychological well-being when compared to other populations (Demir and Weitekamp 2007; Kroenke et al. 2009). The most typical DIY activities that participants engaged in involved aesthetics: making interior or exterior more beautiful; followed by repair, upkeep and maintenance; followed by landscape or gardening; and then constructing new things. Our sample reported very strong interest in their DIY activity, they engaged in these activities regularly, they reported having greater than average skill, and they found the DIY activities as very challenging.

\subsection{Limitations}

There are several limitations to our study. First, mTurk respondents who expressed interest in our DIY study may have been motivated for purely financial reasons. This is not likely, given the low credit paid (they were paid $\$ 1.50$ for participating), and, that investigators have reported that many people who participate in mTurk are internally motivated and interested in learning (Buhrmester et al. 2011; Straszewski and Siegel 2018).

Second, despite taking measures to ensure a normal sample, there is risk the sample may not be a true representation of the DIY population. The respondents in the current study were highly educated, mostly employed, and reported moderate to high incomes; this is similar to samples in previous research on DIY (Wolf and McQuitty 2013). We also included a validity check to ensure that we were only including participants who were engaged in true DIY activities.

Third, another limitation to our study is that we relied on questions that were all retrospective in nature. For example, DIYers were asked to recall how they felt (in general) during their favorite DIY activity. Their actual responses were not assessed while they were engaged in the actual DIY activities. This could have confounded the results, leading to memory bias and a response set when answering the questions. Future research could examine the extent to which the model factors are measurable during an actual DIY activity by using the Experience Sampling Method (Csikszentmihalyi and Larson 2014), as well as by engaging participants in a laboratory analogue of the study. 
Finally, participants answered an ad about DIY experiences. It is likely that interested participants enjoyed DIY activities and have had positive experiences with it, increasing their motivation to be in the study. This could have contributed to a positive response set when answering the questions, e.g., they reported high positive mood and engagement during DIY activities and answered all questions accordingly. This further emphasizes the need for experimental studies to decrease the recall bias.

\section{Conclusion}

Taken together, our findings highlight the advantage sof positive mood/arousal during DIY activities, and indirectly, the importance of flow and the absence of negative selffocus. The SWB benefits of DIY activities are more likely to occur in adults that report low depression and anxiety, as well as high quiet ego characteristics. Our study contributes to the literature by describing the mechanisms responsible for how DIY activities promote SWB, as well as by explaining the factors that optimize the impact of these experiences (Csikszentmihalyi 1990).

Data The authors have full control of all primary data and if published, we agree to allow the journal to review our data, if requested.

Funding None.

\section{Compliance with Ethical Standards}

Conflict of Interest On behalf of all authors, the corresponding author states that there is no conflict of interest.

\section{References}

Asakawa, K. (2004). Flow experience and autotelic personality in Japanese college students: How do they experience challenges in daily life? Journal of Happiness Studies, 5, 123-154.

Augustine, A. A., \& Hemenover, S. H. (2009). On the relative effectiveness of affect regulation strategies: A meta-analysis. Cognition \& Emotion, 23, 1181-1220.

Barrett, L. F., \& Russell, J. A. (1999). The structure of current affect: Controversies and emerging consensus. Current Directions in Psychological Science, 8(1), 10-14.

Bentler, P. M. (2006). EQS 6 structural equations program manual. Multivariate Software, Inc.

Brinck, I. (2017). Empathy, engagement, entrainment: The interaction dynamics of aesthetic experience. Cogn Process, 1-13.

Bryant, F. B., \& Veroff, J. (2007). Savoring: A new model of positive experience. Erlbaum Publishers.

Buhrmester, M., Kwang, T., \& Gosling, S. D. (2011). Amazon's mechanical Turk: A new source of inexpensive, yet high quality, data? Psychological Science, 6, 3-5.

Carroll, J. M., Yik, M. S., Russell, J. A., \& Barrett, L. F. (1999). On the psychometric principles of affect. Review of General Psychology, 3(1), 14-22.

Chartier, I. S., \& Provencher, M. D. (2013). Behavioural activation for depression: Efficacy, effectiveness and dissemination. Journal of Affective Disorders, 145, 292-299.

Collier, A. F. (2011). The well-being of women who create with textiles: Implications for art therapy. Art Therapy, 28, 104-112.

Collier, A. F., \& von Károlyi, C. (2014). Rejuvenation in the "making": Lingering mood repair in textile handcrafters. Psychology of Aesthetics, Creativity, and the Arts, 8, 475. 
Collier, A. F., \& Wayment, H. A. (2018). Psychological benefits of the "maker" or do-it-yourself movement in young adults: A pathway towards subjective well-being. Journal of Happiness Studies, 19, 1217-1239.

Collier, A.F. \& Wayment, H. A. (2019a). Enhancing and explaining art-making for mood-repair: The benefits of positive growth-oriented instructions and quiet ego contemplation. Psychology of Aesthetics, Creativity, and the Arts.

Collier, A. F. \& Wayment, H. A. (2019b). The Benefits of Awe-Inspiring Virtual Reality Experiences for Depressed and Anxious College Students: Engagement and Reduced Ruminative Thought. Manuscript submitted for publication.

Collier, A. F., Wayment, H. A., \& Birkett, M. (2016). Impact of making textile handcrafts on mood enhancement and inflammatory immune changes. Art Therapy: Journal of the American Art Therapy Association, 33(4), 178-185. https://doi.org/10.1080/07421656.2016.1226647

Collins, A. L., Sarkisian, N., \& Winner, E. (2009). Flow and happiness in later life: An investigation into the role of daily and weekly flow experiences. Journal of Happiness Studies, 10, 703-719.

Csikszentmihalyi, M. (1990). Flow: The psychology of optimal experience. Harper \& Row.

Csikszentmihalyi, M., \& Larson, R. (2014). Validity and reliability of the experience-sampling method. In Flow and the foundations of positive psychology (pp. 35-54). Springer Netherlands.

Dalebroux, A., Goldstein, T. R., \& Winner, E. (2008). Short-term mood repair through art-making: Positive emotion is more effective than venting. Motivation and Emotion, 32, 288-295.

Demir, M., \& Weitekamp, L. A. (2007). I'm so happy' cause today I found my friend: Friendship and personality as predictors of happiness. Journal of Happiness Studies, 8, 181-211.

Diener, E. D. (1984). Subjective well-being. Psychological Bulletin, 95, 542.

Diener, E. D. (1994). Assessing subjective well-being: Progress and opportunities. Social Indicators Research, 31, 103-157.

Diener, E., \& Chan, M. (2011). Happy people live longer: Subjective well-being contributes to health and longevity. Applied Psychology: Health and Well-Being, 3, 1-43.

Diener, E., \& Seligman, M. E. (2002). Very happy people. Psychological Science, 13, 81-84. https://doi. org/10.1111/1467-9280.00415.

Diener, E. D., Emmons, R. A., Larsen, R. J., \& Griffin, S. (1985). The satisfaction with life scale. Journal of Personality Assessment, 49, 71-75. https://doi.org/10.1037/cap0000063.

Diener, E., Suh, E. M., Lucas, R. E., \& Smith, H. L. (1999). Subjective well-being: Three decades of progress. Psychological Bulletin, 125, 276.

Diener, E., Oishi, S., \& Lucas, R. E. (2015). National accounts of subjective well-being. The American Psychologist, 70, 234-242. https://doi.org/10.1037/a0038899.

Diener, E., Heintzelman, S. J., Kushlev, K., Tay, L., Wirtz, D., Lutes, L. D., \& Oishi, S. (2017). Findings all psychologists should know from the new science on subjective well-being. Canadian Psychology/ Psychologie Canadienne, 58(2), 87.

Gratz, K. L., Weiss, N. H., \& Tull, M. T. (2015). Examining emotion regulation as an outcome, mechanism, or target of psychological treatments. Current Opinion in Psychology, 3, 85-90.

Griffiths, S. (2008). The experience of creative activity as a treatment medium. Journal of Mental Health, 17, 49-63.

Hirao, K., Kobayashi, R., Okishima, K., \& Tomokuni, Y. (2012). Flow experience and health-related quality of life in community dwelling elderly Japanese. Nursing \& Health Sciences, 14, 52-57.

Kroenke, K., Spitzer, R. L., Williams, J. B. W., \& Lowe, B. (2009). An ultra-brief screening scale for anxiety and depression: The PQH-4. Psychosomatics: Journal of Consultation and Liaison Psychiatry, 50, 613621.

Kuppens, P. (2008). Individual differences in the relationship between pleasure and arousal. Journal of Research in Personality, 42(4), 1053-1059.

Kuppens, P., Tuerlinckx, F., Russell, J. A., \& Barrett, L. F. (2013). The relation between valence and arousal in subjective experience. Psychol Bull, 139, 917.

Kuznetsov, S., \& Paulos, E. (2010). Rise of the expert amateur: DIY projects, communities, and cultures. In Proceedings of the 6th Nordic Conference on Human-Computer Interaction: Extending Boundaries (pp. 295-304). ACM.

Lount Jr., R. B. (2010). The impact of positive mood on trust in interper- sonal and intergroup interactions. Journal of Personality and Social Psychology, 98, 420-433. https://doi.org/10.1037/a0017344.

Lyubomirsky, S., \& Layous, K. (2013). How do simple positive activities increase well-being? Current Directions in Psychological Science, 22, 57-62. https://doi.org/10.1177/0963721412469809.

Lyubomirsky, S., King, L., \& Diener, E. (2005a). The benefits of frequent positive affect: Does happiness lead to success? Psychological Bulletin, 131, 803-855. https://doi.org/10.1037/0033-2909.131.6.803. 
Lyubomirsky, S., Sheldon, K. M., \& Schkade, D. (2005b). Pursuing happiness: The architecture of sustainable change. Review of General Psychology, 9, 111-131.

Lyubomirsky, S., Dickerhoof, R., Boehm, J. K., \& Sheldon, K. M. (2011). Becoming happier takes both a will and a proper way: An experimental longitudinal intervention to boost well-being. Emotion, 11, 391-402. https://doi.org/10.1037/a0022575.

Marin, M. M., Lampatz, A., Wandl, M., \& Leder, H. (2016). Berlyne revisited Evidence for the multifaceted nature of hedonic tone in the appreciation of paintings and music Frontiers in Human Neuroscience, 10.

Martin, F., \& Oliver, T. (2018). Behavioral activation for children and adolescents: A systematic review of progress and promise. European Child \& Adolescent Psychiatry. Advance online publication. https://doi. org/10.1007/s00787-018-1126-Z

McAndrew, L. M., Held, R. F., Abbi, B., Quigley, K. S., Helmer, D. A., Pasupuleti, R. V., \& Chandler, H. K. (2017). Less engagement in pleasurable activities is associated with poorer quality of life for veterans with comorbid postdeployment conditions. Military Psychology, 29, 74-81. https://doi.org/10.1037 /mil0000139.

Mosing, M. A., Butkovic, A., \& Ullen, F. (2018). Can flow experiences be protective of work-related depressive symptoms and burnout? A genetically informative approach. Journal of Affective Disorders, 226, 6-11.

Naragon-Gainey, K., McMahon, T. P., \& Chacko, T. P. (2017). The structure of common emotion regulation strategies: A meta-analytic examination. Psychological Bulletin, 143, 384.

Nolen-Hoeksema, S., Wisco, B. E., \& Lyubomirsky, S. (2008). Rethinking rumination. Perspectives on Psychological Science, 3(5), 400-424.

Peifer, C., Schächinger, H., Engeser, S., \& Antoni, C. H. (2015). Cortisol effects on flow-experience. Psychopharmacology, 232(6), 1165-1173.

Pinquart, M., \& Forstmeier, S. (2012). Effects of reminiscence interven- tions on psychosocial outcomes: A meta-analysis. Aging \& Mental Health, 16, 541-558. https://doi.org/10.1080/13607863.2011.651434.

Pöllänen, S. H. (2015a). Elements of crafts that enhance well-being: Textile craft makers' descriptions of their leisure activity. Journal of Leisure Research, 47, 58.

Pöllänen, S. H. (2015b). Crafts as leisure-based coping: Craft makers' descriptions of their stress-reducing activity. Occupational Therapy in Mental Health, 31, 83-100.

Rogatko, T. P. (2009). The influence of flow on positive affect in college students. Journal of Happiness Studies, 10, 133.

Rusting, C. L., \& Nolen-Hoeksema, S. (1998). Regulating responses to anger: Effects of rumination and distraction on angry mood. Journal of Personality and Social Psychology, 74(3), 790.

Sahoo, F. M., \& Sahu, R. (2009). The role of flow experience in human happiness. Journal of the Indian Academy of Applied Psychology, 35, 40-47.

Sheldon, K. M., \& Lyubomirsky, S. (2006). Achieving sustainable gains in happiness: Change your actions, not your circumstances. Journal of Happiness Studies, 7, 55-86.

Sheldon, K. M., \& Lyubomirsky, S. (2019). Revisiting the sustainable happiness model and pie chart: Can happiness be successfully pursued? The Journal of Positive Psychology, 1-10. https://doi.org/10.1080 $/ 17439760.2019 .1689421$.

Sheldon, K. M., Boehm, J. K., \& Lyubomirsky, S. (2012). Variety is the spice of happiness: The hedonic adaptation prevention (HAP) model. In I. Boniwell \& S. David (Eds.), Oxford handbook of happiness (pp. 901-914). Oxford University Press.

Soucy, I. C., Blanchet, V., \& Provencher, M. D. (2013). Behavioral activation and depression: A contextual treatment approach. Sante mentale au Quebec, 38(2), 175-194.

Spitzer, R. L., Kroenke, K., \& Williams, J. B. W. (1999). Validation and utility of a self-report version of PRIME-MD. JAMA, 282, 1737-1744.

Straszewski, T., \& Siegel, J. T. (2018). Positive emotion infusions: Can savoring increase help-seeking intentions among people with depression? Applied Psychology: Health and Well-Being, 10, 171-190.

Thayer, R. E., Newman, J. R., \& McClain, T. M. (1994). Self-regulation of mood: Strategies for changing a bad mood, raising energy, and reducing tension. Journal of Personality and Social Psychology, 67, 910.

Treynor, W., Gonzalez, R., \& Nolen-Hoeksema, S. (2003). Rumination reconsidered: A psychometric analysis. Cognitive Therapy and Research, 27, 247-259.

Waterman, A. S., Schwartz, S. J., \& Conti, R. (2008). The implications of two conceptions of happiness (hedonic enjoyment and eudemonia) for the understanding of intrinsic motivation. Journal of Happiness Studies, 9, 41-79.

Watson, D., Clark, L. A., \& Tellegen, A. (1988). Development and validation of brief measures of positive and negative affect: The PANAS scales. Journal of Personality and Social Psychology, 54, 1063. 
Wayment, H. A. (2008). In J. Bauer (Ed.), Transcending self-interest: Psychological explorations of the quiet ego. American Psychological Association.

Wayment, H. A., \& Bauer, J. J. (2017). The quiet ego: Concept, measurement, and well-being. In M. D. Robinson \& M. Eid (Eds.), The happy mind: Cognitive contributions to well-being. Springer Publishing.

Wayment, H. A., \& Bauer, J. J. (2018). The quiet ego: Motives for self-other balance and growth in relation to well-being. Journal of Happiness Studies, 19(3), 881-896.

Wayment, H. A., \& Brookshire, K. A. (2018). Mothers' reactions to their Child's ASD diagnosis: Predictors that discriminate grief from distress. Journal of Autism and Developmental Disorders, 48, 1147-1158.

Wayment, H. A., \& Silver, R. C. (2018). Grief and solidarity reactions 1 week after an on-campus shooting. Journal of Interpersonal Violence, 0886260518766431.

Wayment, H. A., \& Walters, A. S. (2017). Goal orientation and well-being in college athletes: The importance of athletic social connectedness. Journal of Sports Sciences, 35(21), 2114-2120.

Wayment, H. A., Bauer, J. J., \& Sylaska, K. (2015). The quiet ego scale: Measuring the compassionate selfidentity. Journal of Happiness Studies, 16, 999-1033.

Wayment, H. A., West, T., \& Craddock, E. (2016). Compassionate values as a resource during the transition to college: Quiet ego, compassionate goals, and self-compassion. Journal of the First-Year Experience \& Students in Transition, 28(2), 93-114.

Williams, C. C. (2008). Re-thinking the motives of do-it-yourself (DIY) consumers. The International Review of Retail, Distribution and Consumer Research, 18, 311-323.

Williams, Z. (2013). 10 characteristics of the DIY consumer. DIY Home Improvement and Maintenance - US Chicago: Mintel Group Ltd https://wwwvenveocom/blog/10-characteristics-of-the-diy-consumer/ September 25, 2018.

Wolf, M., \& McQuitty, S. (2011). Understanding the do-it-yourself consumer: DIY motivations and outcomes. Academy of Marketing Science Review, 1, 154-170.

Wolf, M., \& McQuitty, S. (2013). Circumventing traditional markets: An empirical study of the marketplace motivations and outcomes of consumers' do-it-yourself behaviors. Journal of Marketing Theory and Practice, 21, 195-210.

Wolf, M., \& Ritz, W. (2018). When sharing was a necessity: A historical perspective of collaborative consumption in East Germany. In P. A. Albinsson \& B. Y. Perera (Eds.), The rise of the sharing economy: Exploring the challenges and opportunities of collaborative consumption. Praeger Publishing.

Wolf, M., Albinsson, P., \& Becker, C. (2015). DIY projects as path toward female empowerment in a gendered marketplace. Psychology and Marketing, 28, 133-143.

Publisher's Note Springer Nature remains neutral with regard to jurisdictional claims in published maps and institutional affiliations. 